\title{
The effect of calcium-induced fullerene migration on the performance of thermally stable nanoparticle organic solar cells
}

\author{
K. Feron, ${ }^{1,2, a)}$ S. Ulum, ${ }^{2,3}$ E. Sesa, ${ }^{2,3}$ B. B. Gong, ${ }^{4}$ W. J. Belcher, ${ }^{2}$ X. Zhou, ${ }^{2}$ C. J. Fell, ${ }^{1,2}$ \\ and P. C. Dastoor ${ }^{2}$ \\ ${ }^{1}$ CSIRO Energy Technology, Newcastle NSW 2300, Australia \\ ${ }^{2}$ University of Newcastle, Centre for Organic Electronics, Newcastle, NSW 2308, Australia \\ ${ }^{3}$ Physics Department, Tadulako University, Palu, Indonesia \\ ${ }^{4}$ Mark Wainwright Analytical Centre, University of New South Wales, Sydney NSW 2052, Australia
}

(Received 29 July 2014; accepted 10 September 2014; published online 22 September 2014)

\begin{abstract}
The impact of a calcium interface layer in combination with a thermal annealing treatment on the performance of poly(3-hexylthiophene) (P3HT):[6,6]-phenyl-C61-buteric acid methylester (PCBM) nanoparticle photovoltaic devices is investigated. Annealing is found to disrupt the microstructure of the nanoparticle active layer leading to a reduction in fill factor. However, X-ray photoelectron spectroscopy measurements show that the calcium interface layer causes PCBM to preferentially migrate to the cathode interface upon annealing, resulting in better charge extraction from the PCBM moiety, an increase in the built-in voltage, open-circuit voltage, and power conversion efficiency. Moreover, the annealing trends could be completely explained by the observed PCBM migration. Unlike P3HT:PCBM bulk heterojunction devices, the P3HT:PCBM nanoparticle devices showed a remarkable thermal stability up to $120^{\circ} \mathrm{C}$. As such, OPVs fabricated from aqueous nanoparticle inks provide an attractive alternative to conventional organic solvent based bulk heterojunction devices. (C) 2014 AIP Publishing LLC. [http://dx.doi.org/10.1063/1.4896249]
\end{abstract}

\section{INTRODUCTION}

Much recent research effort has been focussed on organic solar cells due to their potential as a low-cost sustainable energy source. ${ }^{1}$ In particular, bulk heterojunction (BHJ) structures fabricated using organic solvents have received considerable interest. ${ }^{2}$ However, there are two disadvantages associated with traditional BHJ structures. First, the use of organic solvents poses significant environmental, health and safety risks, especially with regard to deposition via large scale printing techniques. ${ }^{3,4}$ The second drawback is the thermal stability of BHJ structures. It has been shown that various polymer:fullerene BHJ devices, including the commonly used poly(3-hexylthiophene) (P3HT):[6,6]-phenylC61-buteric acid methylester (PCBM) system, undergo a considerable drop in performance during long-term operation at elevated temperatures, which arises from significant changes in the film morphology. ${ }^{5}$ Thermal annealing treatments at low temperature (similar to operating temperatures in real-life conditions) already induce a change in the BHJ structure. ${ }^{6}$ Moreover, the optimum morphology for photovoltaic (PV) performance is intrinsically unstable at real-life operating temperatures. ${ }^{7}$ Several approaches have been investigated to overcome this shortcoming by reducing the phase separation of the active components when exposing the device to outside temperature conditions, such as the use of high glass transition temperature materials. ${ }^{5,7}$ However, this approach limits the number of available organic semiconductors for PV applications. In the case of P3HT, reduced regioregularity also improves thermal stability, but results in

\footnotetext{
a) Author to whom correspondence should be addressed. Electronic mail: Krishna.Feron@csiro.au
}

lower power conversion efficiency (PCE). ${ }^{8}$ Alternative approaches to fixing the structure of the active layer have also been attempted via cross-linking ${ }^{9}$ or using compatibilizers. ${ }^{10}$

Recent work in our laboratory has focussed on utilising a mini-emulsion fabrication process that can in principle be applied to any organic semiconductor and allows for deposition from water (as opposed to hazardous solvents). As such, the mini-emulsion fabrication approach eliminates the two key drawbacks of standard BHJ organic solar cells and provides an alternative to the standard fabrication approach that is much more compatible with large-scale printing techniques. As we have shown previously, the resulting structure of the miniemulsion approach is of a nanoparticle (NP) nature typically with a core-shell structure. ${ }^{11-13}$ For P3HT:PCBM NPs, the core predominantly consists of PCBM surrounded by a P3HT rich shell. ${ }^{12}$ Improvement of PCE can be obtained through the use of electrode interface layers, such as calcium $(\mathrm{Ca})$. The specific mechanism for the observed improvement depends on the material system and interface layer used. ${ }^{14}$ We have previously discussed the impact of a $\mathrm{Ca}$ interface layer on NP and BHJ devices made from poly(9,9-dioctylfluorene-co-N,Nbis(4-butylphenyl)-N,Ndiphenyl-1,4-phenylenediamine) (PFB): poly(9,9-dioctylfluorene-co-benzothiadiazol) (F8BT) and showed that the PFB:F8BT NP devices performed better than their BHJ equivalent. ${ }^{15}$

In this manuscript, we report on the effect of thermal annealing upon $\mathrm{Ca}$ interface layers and the notably different performance behaviour that is seen for the P3HT:PCBM NP and BHJ material systems. Using X-ray photoelectron spectroscopy (XPS), current-voltage $(I-V)$ and quantum efficiency measurements, the mechanism behind the Ca-induced performance improvement and resulting annealing trends are 
explained. Significantly, we show that NP organic solar cells have much greater thermal stability than the corresponding BHJ devices.

\section{EXPERIMENTAL ASPECTS}

\section{A. Device fabrication}

Aqueous dispersions of P3HT:PCBM (1:1 weight ratio) NPs were prepared following the mini-emulsion technique as described previously. ${ }^{16}$ PEDOT:PSS (Baytron P) films were spun on pre-cleaned patterned ITO substrates and annealed for $20 \mathrm{~min}$ at $140^{\circ} \mathrm{C}$. P3HT:PCBM NP films were spun from water on top of the PEDOT:PSS layer in air to yield an active layer thickness of approximately $100 \mathrm{~nm}$. The films were dried at $110^{\circ} \mathrm{C}$ for $4 \mathrm{~min}$ before being transferred to the vacuum chamber for cathode evaporation. Devices were made either with or without a $\mathrm{Ca}$ interface layer at the $\mathrm{Al}$ cathode (Ca-Al or $\mathrm{Al})$. The devices were characterised before and after undergoing a thermal annealing treatment of $4 \mathrm{~min}$ at $140^{\circ} \mathrm{C}$.

The procedure for $\mathrm{BHJ}$ devices only differed from the NP fabrication procedure in the active layer. The $\mathrm{BHJ}$ active layer was spin cast from chloroform in a nitrogen environment. All other fabrication steps were the same as for NP devices.

\section{B. Current-voltage measurements}

$I-V$ measurements were conducted using a Keithley 2400 source meter. Devices were illuminated using a Newport class A solar simulator with an AM1.5 spectrum filter. The light intensity was $1000 \mathrm{~W} / \mathrm{m}^{2}$ as confirmed using a calibrated silicon reference solar cell (FHG-ISE).

\section{External quantum efficiency measurements}

External quantum efficiency measurements were recorded when the devices were exposed to light from a tungsten halogen lamp passed through an Oriel Cornerstone 130 monochromator, using an Ithaco Dynatrac 395 analogue lock-in amplifier and Thorlabs PDA55 silicon diode to collect the reference signal, and a Stanford Research Systems SR830 DSP digitising lock-in amplifier to measure device current.

\section{X-ray photoelectron spectroscopy depth profiling measurements}

XPS depth profiling measurements were conducted as described previously. ${ }^{17}$ The areas under the following peaks were tracked: $\mathrm{Al} 2 \mathrm{p}(72.3 \mathrm{eV}), \mathrm{Ca} 2 \mathrm{p}(347.5 \mathrm{eV}), \mathrm{C} 1 \mathrm{~s}$ $(285 \mathrm{eV}), \mathrm{S} 2 \mathrm{p}(164 \mathrm{eV})$, and In $3 \mathrm{~d}(445 \mathrm{eV})$. These measurements were used to probe the presence of aluminium, calcium, carbon, sulphur, and ITO, respectively, as a function of depth. The carbon:sulphur (C:S) ratio was calculated to distinguish between PCBM, P3HT and PEDOT:PSS. ${ }^{18}$

\section{RESULTS AND DISCUSSION}

\section{A. Observed current-voltage characteristics}

P3HT:PCBM NP devices with an Al cathode and with a $\mathrm{Ca}-\mathrm{Al}$ cathode were annealed and the associated change in $I-V$ characteristics were measured, see Table I. For the $\mathrm{Al}$
TABLE I. Performance indicators for P3HT:PCBM NP devices with Al and $\mathrm{Ca}-\mathrm{Al}$ cathodes. Average values were determined from a set of 10 different devices. The maximum value is shown in parentheses.

\begin{tabular}{lccccc}
\hline \hline & & & $\mathrm{J}_{\mathrm{SC}}$ \\
& $\mathrm{V}_{\text {OC }}(\mathrm{V})$ & $\left(\mathrm{mA} / \mathrm{cm}^{2}\right)$ & $\mathrm{FF}(\%)$ & PCE (\%) \\
\hline Al cathode & Before annealing & $0.44(0.47)$ & $3.45(3.66)$ & $42(42)$ & $0.63(0.68)$ \\
& After annealing & $0.29(0.30)$ & $2.15(2.27)$ & $34(34)$ & $0.21(0.23)$ \\
$\mathrm{Ca}-\mathrm{Al}$ & Before annealing & $0.35(0.38)$ & $3.5(3.9)$ & $43(46)$ & $0.54(0.64)$ \\
cathode & After annealing & $0.55(0.58)$ & $3.75(4.12)$ & $41(42)$ & $0.85(1)$ \\
\hline \hline
\end{tabular}

cathode devices $F F, V_{O C}$, short-circuit current density $\left(J_{S C}\right)$ and $P C E$ were observed to decrease after annealing. On the other hand, $\mathrm{Ca}-\mathrm{Al}$ cathode devices did benefit from the annealing treatment as $P C E$ increased.

The $F F, V_{O C}$, and the dark $I-V$ characteristics indicate the processes that occur in the NP devices. First, $F F$ is known to be heavily influenced by charge recombination. ${ }^{19,20}$ The fact that $F F$ decreases after annealing for all devices indicates that recombination increases due to the annealing treatment changing the microstructure of the P3HT:PCBM NP active layer to a less favourable state; consistent with the extensive phase segregation that is known to occur in this NP system. ${ }^{21,22}$ Second, annealing NP films in the presence of a Ca interface layer produces a considerable increase in $V_{O C}$, while $J_{S C}$ changes only slightly. Consequently, the overall improvement in efficiency of the annealed Ca-Al devices is mostly caused by $V_{O C}$. Since $V_{O C}$ is observed to increase despite an increase in recombination, we hypothesise that the $\mathrm{Ca}$ interface layer changes the energy barrier at the organic-cathode interface. Furthermore, dark $I-V$ characteristics of the $\mathrm{Ca}-\mathrm{Al}$ devices exhibit a considerable difference in the diode turn-on voltage, i.e., the voltage required to reach a particular current density value, after annealing (Figure 1), which is indicative of a change in the injection barrier. ${ }^{23}$ Although such a difference in turn-on voltage could be achieved by a change in charge carrier mobility, this explanation seems unlikely given that devices without $\mathrm{Ca}$ did not show the same increase in turn-on voltage.

Further evidence for a change in extraction/injection barriers is found by looking at $V_{0}$, the voltage at which the current under illumination is the same as the current in the dark. We use $V_{0}$ as an approximation of the built-in electric field. Consequently, the effective voltage is given by $V_{0}-V$, where $V$ is the externally applied voltage. As shown in the supplementary material, ${ }^{24} V_{0}$ is largely unaffected by the light intensity (i.e., charge carrier density) and is therefore expected to be unaffected by charge recombination. This property makes $V_{0}$ a reasonable measure for changes in electronic energy levels and/or barriers at electrodes. Figure 2 shows the photocurrent $\left(J_{p h}\right)$ as a function of the effective voltage for devices with $\mathrm{Al}$ and $\mathrm{Ca}-\mathrm{Al}$ cathodes. Both the characteristics before and after annealing are shown. $J_{p h}$ is given by

$$
J_{p h}=J_{L}-J_{D},
$$

where $J_{L}$ is the measured current density under illumination and $J_{D}$ the current density in the dark. The $J_{p h}$ characteristics of devices with $\mathrm{Ca}-\mathrm{Al}$ and $\mathrm{Al}$ cathodes are very similar prior to annealing. Only after annealing do we observe a distinct 
(a)

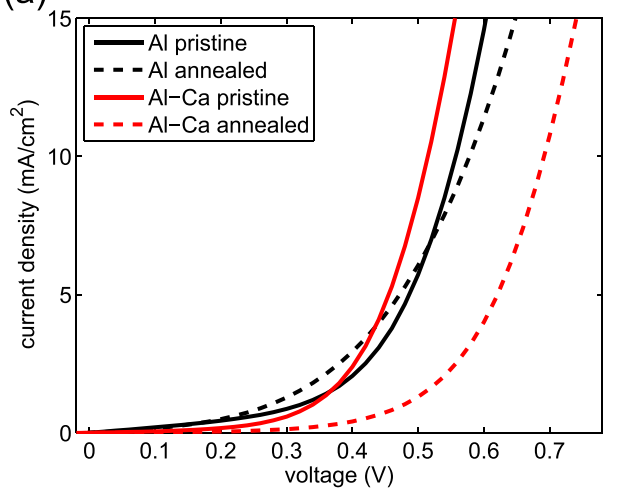

(b)

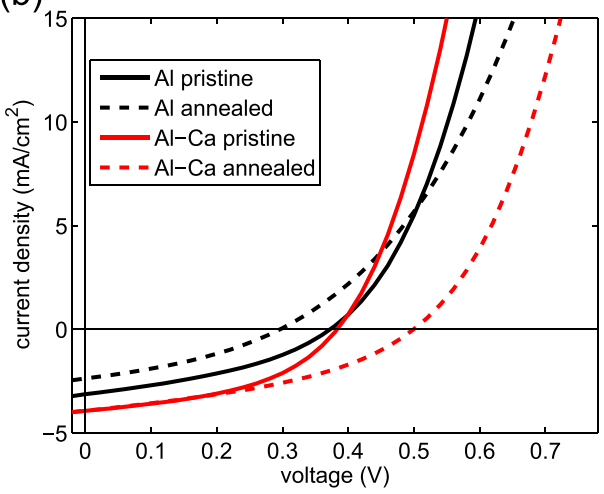

FIG. 1. J-V curves for P3HT:PCBM NP devices measured (a) in the dark and (b) in the light before (solid lines) and after annealing (dashed lines). difference in the $I-V$ curves. Therefore, we can conclude that while the $\mathrm{Ca}$ interface alone does not inherently change the energy barrier at the cathode interface, it does influence how the cathode-organic energy barrier changes upon annealing. In both the $\mathrm{Ca}-\mathrm{Al}$ and the $\mathrm{Al}$ cases, the photocurrent for a given effective voltage decreases after annealing, which explains the corresponding drop in $F F$. As such, the increase in efficiency caused by annealing cannot be explained by a reduction in recombination and, in fact, recombination in the active layer seems to increase after annealing. Annealing is known to decrease the internal quantum efficiency and $J_{S C}$ when nanoparticles are used, ${ }^{22}$ which is consistent with the results in Figure 2. Figure 2 also shows why the overall efficiency still increased and $J_{S C}$ need not decrease after annealing despite increased recombination. $V_{0}$, as indicated by the arrows, increases considerably after annealing when $\mathrm{Ca}$ is used. After annealing, $V_{0}$ was observed to increase by $0.1 \mathrm{~V}$ when a $\mathrm{Ca}$ interface layer is used and only $0.01 \mathrm{~V}$ when an Al cathode was used. In other words, the device operates at a higher effective voltage due to an increase in the built-in field, which results in a larger $V_{O C}$ and offsets the impact of additional recombination on $J_{S C}$.

In summary, the $I-V$ data indicate that $\mathrm{Ca}$ induces two effects that lead to changes in the overall efficiency. First, annealing produces a bulk active layer that exhibits more recombination and when a $\mathrm{Ca}$ interface layer is used this

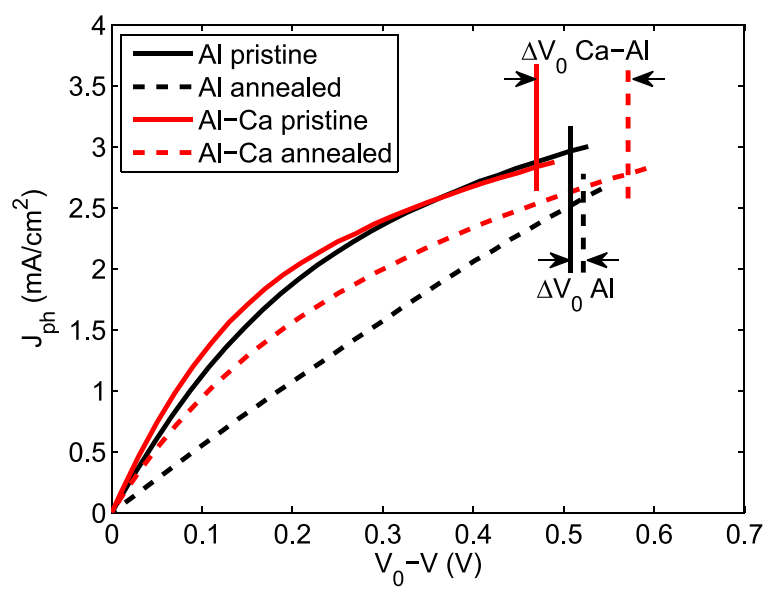

FIG. 2. $J_{p h}$ as a function of $V_{0^{-}} V$ for P3HT:PCBM NP devices with $\mathrm{Al}$ and Al-Ca cathodes before and after annealing. Vertical lines indicate the location of $J_{S C}$ and $\mathrm{V}_{0}$. The difference in $\mathrm{V}_{0}$ before and after annealing is indicated with arrows for an $\mathrm{Al}$ cathode device and $\mathrm{Ca}-\mathrm{Al}$ cathode device. increase in recombination is lessened. Second, when $\mathrm{Ca}$ is used as an interface layer, annealing produces a considerable increase in the built-in electric field, which results in a significantly higher $V_{O C}$ and is the main cause of the observed increase in overall efficiency.

\section{B. Ca-induced changes in external quantum efficiency behaviour}

Figure 3(a) shows external quantum efficiency measurements for devices with an aluminium cathode before and after annealing. The same EQE spectra are also shown in (b), but the spectra that were measured after annealing were multiplied by a constant so that the region around $600 \mathrm{~nm}$ matched the spectra as measured before the annealing treatment.

In the case of $\mathrm{Al}$ cathodes, annealing is observed to cause an overall decrease in EQE (Figure 3(a)). Furthermore, Figure 3(b) reveals that annealing causes an additional relative decrease in EQE for wavelengths $<500 \mathrm{~nm}$. The absolute photocurrent contribution of PCBM rapidly increases for wavelengths $<500 \mathrm{~nm}$ (Ref. 25) and thus annealing decreases the photocurrent contribution of PCBM more than that of P3HT for devices with Al cathodes. Devices with Al$\mathrm{Ca}$ cathodes exhibit an opposite effect; the PCBM contribution to the total photocurrent increases after annealing. In fact, this increase at the short wavelength end compensates for the loss in photocurrent in the rest of the spectrum explaining why the $J_{S C}$ of $\mathrm{Ca}-\mathrm{Al}$ devices does not change much after annealing. The EQE spectra corresponding to both pristine (i.e., unannealed) devices are similar in shape, which indicates that the $\mathrm{Ca}$ interface layer does not inherently affect the relative photocurrent contributions of PCBM or $\mathrm{P} 3 \mathrm{HT}$. However, as also observed in the $I-V$ characteristics, the annealed $\mathrm{Ca}-\mathrm{Al}$ devices perform quite differently to the annealed Al devices. The EQE spectra show that charge extraction from the PCBM moiety in particular is considerably affected by the thermal annealing treatment; consistent with the known migration and phase segregation of PCBM for this system. ${ }^{21}$ When a Ca interface layer is used, charge extraction from the PCBM moiety is more efficient, but in the absence of $\mathrm{Ca}$, charge extraction from PCBM is considerably less efficient. PCBM is predominantly located in the cores of pristine $\mathrm{NPs}^{12,21}$ and electrons have to travel through one or more $\mathrm{P} 3 \mathrm{HT}$ rich shell(s). Considering that the 
(a)

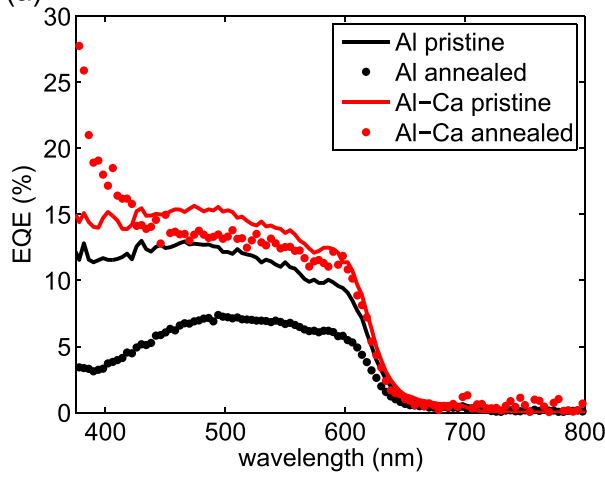

(b)

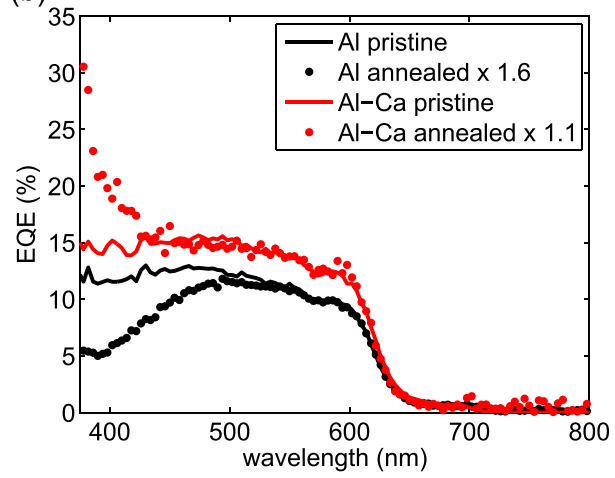

FIG. 3. (a) EQE spectra of P3HT:PCBM NP devices with Al or $\mathrm{Al}-\mathrm{Ca}$ cathodes as per legend. (b) EQE spectra, where the annealed spectra are multiplied by a constant to match the right side of the pristine spectra. latter process is expected to limit electron extraction, ${ }^{22}$ it is likely that $\mathrm{Ca}$ confined (as opposed to $\mathrm{Al}$ confined) annealing leads to better charge carrier percolation pathways of PCBM to the cathode, which is why reduced recombination was observed in the $I-V$ characteristics of the $\mathrm{Ca}-\mathrm{Al}$ devices as compared to the $\mathrm{Al}$ devices.

\section{XPS depth profiling}

In order to determine how Ca changes the built-in electric field after annealing, we conducted XPS depth profiling measurements. Figure 4 shows a typical XPS depth profile where the $\mathrm{Al} 2 \mathrm{p}$ signal acts as a marker for the aluminium cathode, $\mathrm{C} 1 \mathrm{~s}$ and $\mathrm{S} 2 \mathrm{p}$ for the active layer and PEDOT:PSS layer, $\mathrm{Ca} 2 \mathrm{p}$ for the calcium interface layer and $\mathrm{In} 3 \mathrm{~d}$ for the ITO anode.

Figure 5 shows the $\mathrm{Ca}$ concentration depth profile for the pristine and annealed NP films and reveals that the $\mathrm{Ca}$ distribution does not significantly change after annealing, indicating that the thermal treatment does not induce $\mathrm{Ca}$ diffusion in the film.

The PCBM:P3HT weight ratio was calculated using the carbon:sulphur ratio, molecular formulae, and molecular weights of PCBM and P3HT. In order to determine whether diffusion of the photoactive components in the plane perpendicular to the device takes place we introduce the variable $\mathrm{C}_{\mathrm{a} / \mathrm{p}}$, which is given by the quotient of the PCBM:P3HT weight ratio for an annealed device and that for an equivalent

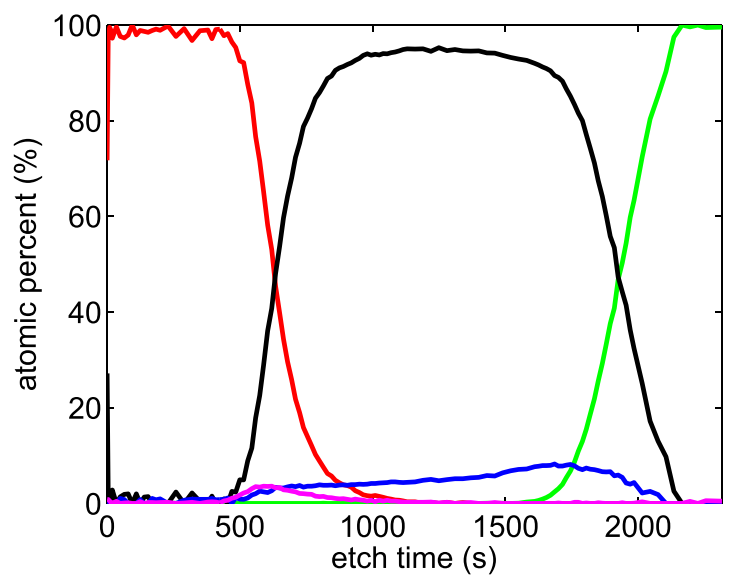

FIG. 4. XPS depth profile of a P3HT:PCBM NP device with a Ca-Al cathode showing aluminium (red), calcium (magenta), carbon (black), sulphur (blue), and indium (green). pristine device. The reader is referred to supplementary material for more details on the calculation of $\mathrm{C}_{\mathrm{a} / \mathrm{p}} \cdot{ }^{24} \mathrm{~A} \mathrm{C}_{\mathrm{a} / \mathrm{p}}$ value greater than unity indicates that the local PCBM content has increased after annealing. Figure 6 shows $C_{a / p}$ as a function of depth for devices with an $\mathrm{Al}$ cathode and devices with a $\mathrm{Ca}-\mathrm{Al}$ cathode. The $\mathrm{y}$-axis is positioned at the cathode interface, which is defined by convention as the half-way point between the $80 \%$ and $20 \%$ signal intensity levels for the Al 2 p signal. ${ }^{26}$ Figure 6 (a) shows that the annealing treatment does not change the vertical distribution of PCBM:P3HT in NP devices with Al cathodes. However, as shown in Figure 6(b), when a $\mathrm{Ca}$ interface layer is used considerable PCBM diffusion towards the cathode interface takes place during the thermal annealing treatment.

It is known that the surface energy of the material contacting the P3HT:PCBM layer influences the P3HT:PCBM composition at the corresponding interface. ${ }^{27,28}$ Surface energy gradients have been shown to drive molecular diffusion in a preferred direction. ${ }^{29,30}$ Hence, it is likely that $\mathrm{Ca}$ has a different surface energy to $\mathrm{Al}$ and increases the driving force of PCBM migration towards the cathode. However, the P3HT:PCBM composition can only redistribute if sufficient energy is available for molecular diffusion. As a result, PCBM diffusion with a preferred direction occurs at the annealing temperature for a device with a $\mathrm{Ca}-\mathrm{Al}$ cathode. The surface energy of the Al cathode is not sufficient to drive migration of PCBM out of the NP cores to the cathode even when annealing.

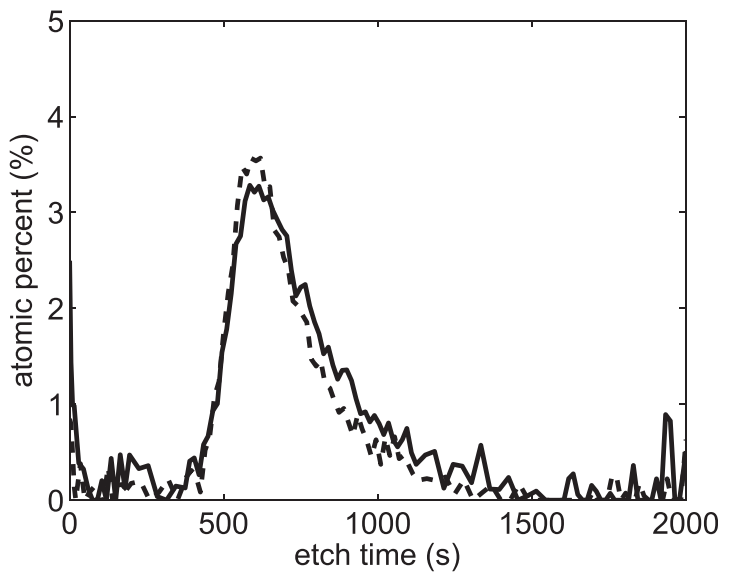

FIG. 5. Ca signal for a pristine (dashed line) and an annealed (solid line) P3HT:PCBM NP device with a Ca interface layer. 

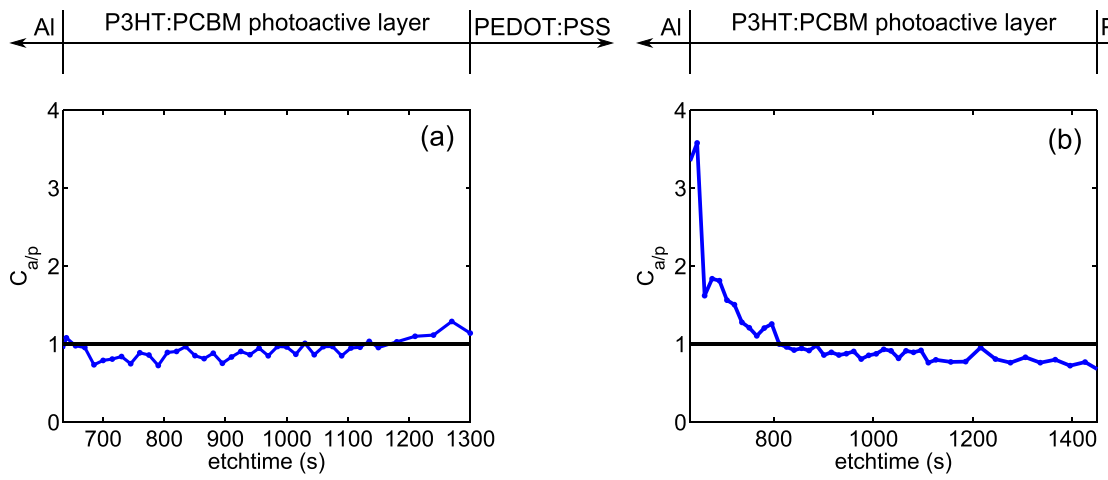

$\stackrel{P E D O T: P S S}{\longrightarrow}$

It is clear from the XPS results that both $\mathrm{Ca}$ and an annealing treatment are necessary to induce a vertical reorganisation in the PCBM:P3HT ratio in NP devices. On the other hand, we have already shown that thermally annealing $\mathrm{BHJ}$ devices with an $\mathrm{Al}$ cathode (in the absence of $\mathrm{Ca}$ ) already induces PCBM diffusion towards the cathode interface. ${ }^{18}$ Since the same is clearly not true for the equivalent NP structured device (Figure 6(a)), it appears that the NP structure is less prone to diffusion of the active constituents. In other words, the NP structures have better inherent thermal stability compared to equivalent BHJ structures.

The PCBM concentration at the cathode affects the charge extraction barrier, $V_{0}$ and thus $V_{O C} \cdot{ }^{31}$ Zhang et al. found that ambipolar structures exhibit a strong dependence of $V_{O C}$ on the nature of the cathode (i.e., work function and interface layer) while unipolar structures show only a weak dependence of $V_{O C}$ on the electrodes. ${ }^{32}$ Since NP structures allow for ambipolar charge extraction, a strong dependence on the interface layer is expected. We quantify the relationship between $V_{O C}$ and the PCBM concentration at the cathode interface (mid-way between the $20 \%$ and $80 \% \mathrm{C}$ 1s signal) for both NP and BHJ devices in Figure 7. The results include devices with an $\mathrm{Al}$ cathode and a $\mathrm{Ca}-\mathrm{Al}$ cathode before and after annealing, thus giving rise to four data

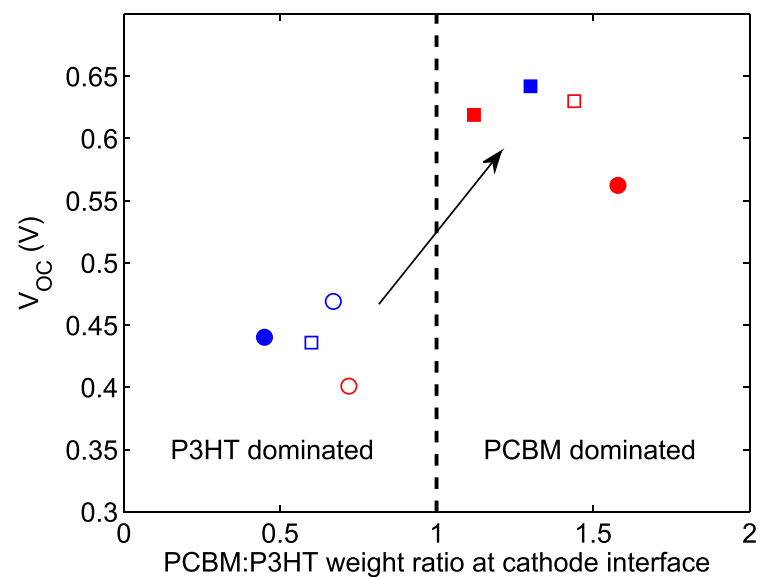

FIG. 7. $V_{O C}$ as a function of the PCBM:P3HT weight ratio at the cathode interface for NP devices (circles) and BHJ devices (squares). The PCBM:P3HT weight ratio at the cathode interface was changed by using either $\mathrm{Ca}-\mathrm{Al}$ or $\mathrm{Al}$ cathode and/or thermal annealing, thus giving rise to four combinations for each structure (NP vs BHJ). Annealed devices are depicted in red and pristine devices in blue. Devices with an Al cathode are depicted with open symbols and Ca-Al with filled symbols. The black dashed line indicates an interface that is equally in contact with PCBM and P3HT. points per structure (NP, BHJ). $V_{O C}$ shows a clear dependence on the PCBM:P3HT weight ratio at the cathode. When the cathode interface is dominated by $\mathrm{P} 3 \mathrm{HT}, V_{O C}$ is reduced by roughly $0.2 \mathrm{~V}$ compared to a PCBM dominated interface. The $V_{O C}$ of the NP device with the highest PCBM concentration at the cathode was approximately $0.08 \mathrm{~V}$ lower than the equivalent PCBM dominated cathode BHJ device. This observation is explained by considering that $V_{O C}$ is not only affected by interface processes, but also bulk (bimolecular) recombination. ${ }^{33,34}$ Since annealed NP devices exhibit more recombination than their BHJ equivalents, ${ }^{22}$ annealed NP devices do not achieve the same $V_{O C}$ despite a favourable PCBM coverage of the cathode. On the other hand, the pristine devices exhibit similar $V_{O C}$ irrespective of the nature of the structure (NP vs BHJ). The pristine devices showed similar $F F$ irrespective of the nature of the structure, which indicates that bimolecular recombination in $\mathrm{NP}$ and $\mathrm{BHJ}$ pristine devices is approximately the same. ${ }^{19,20}$

Considering the results in Secs. III A and III B together with the XPS depth profiling data, a clearer picture of the Ca-induced effects upon device performance emerges. PCBM diffusion toward the cathode interface gives rise to a lower average energy barrier at the cathode and thus a higher built-in voltage and $V_{O C}$. Furthermore, the increased contact of PCBM with the cathode allows for better charge extraction from the PCBM moiety, which explains the increase in EQE at wavelengths $<500 \mathrm{~nm}$. While annealing improves the organic-cathode contact, it has a detrimental effect on the photocharge generation process in the bulk of the active layer. $F F$ decreases after annealing due to increased charge recombination and $J_{S C}$ remains similar despite an increase in the effective electric field. Finally, the increase in built-in voltage outweighs the poorer performing microstructure of the active layer and an increase in $P C E$ is observed.

\section{Annealing trends in nanoparticle-structured devices}

The described Ca-induced mechanism also explains annealing trends of NP devices. The thermal annealing process has two parameters that affect the way the microstructure changes: annealing time and temperature. Longer annealing duration above the glass transition temperature gives the mobile photoactive components more opportunity to diffuse and reorganise. A higher temperature would give the photoactive components more energy to diffuse as well. As such, a higher PCBM concentration at the cathode 
(a)

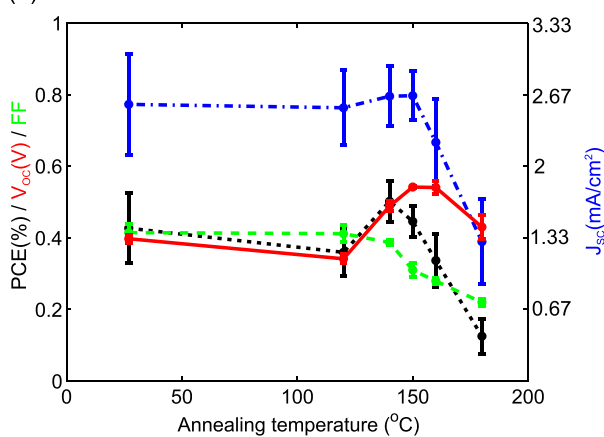

(b)

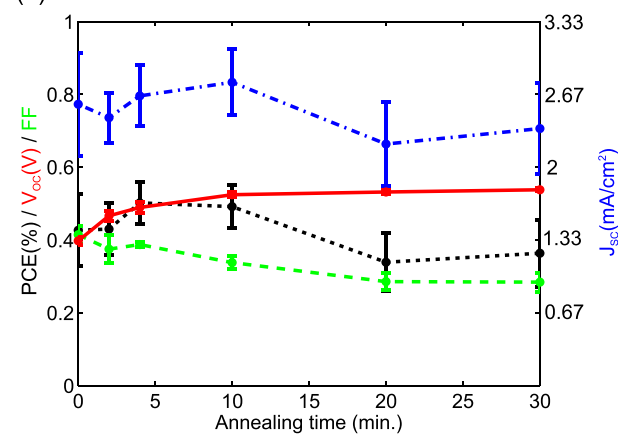

FIG. 8. $P C E$ (black, short dash), $J_{S C}$, (blue, dashed-dotted) $V_{O C}$ (red, solid), and $F F$ (green, long dash) of P3HT:PCBM NP devices as a function of (a) annealing temperature while keeping the annealing time fixed at $4 \mathrm{~min}$. and (b) annealing time while keeping the annealing temperature fixed at $140{ }^{\circ} \mathrm{C}$. interface and thus higher $V_{O C}$ is expected when annealing for longer periods of time or at higher temperatures. Figure 8 shows the annealing trends for NP devices with $\mathrm{Ca}-\mathrm{Al}$ cathodes. Unlike BHJ structures, ${ }^{6}$ the parameters of NP devices do not change significantly when annealed at $120^{\circ} \mathrm{C}$ or lower. Only at temperatures higher than $120^{\circ} \mathrm{C}$, which corresponds with the glass transition temperature of $\mathrm{PCBM}^{7}$ is PCBM mobile enough to migrate to the cathode interface and consequently increase $V_{O C}$. The annealing induced change in the microstructure of the active layer, however, does cause the $F F$ to decrease and it continues to decrease as PCBM becomes more mobile. Since $V_{O C}$ is affected by both the active layer-cathode contact and bimolecular recombination, an optimum temperature exists for $V_{O C}$. This optimum is at $150-160{ }^{\circ} \mathrm{C}$. For temperatures higher than $160^{\circ} \mathrm{C}$, recombination is sufficiently prevalent so as to counteract the favourable effect of the high PCBM concentration at the cathode contact, resulting in $V_{O C}$ decreasing. When $F F<0.28$, bimolecular recombination is efficient enough to cause a reduction in $V_{O C}$ despite a favourable energy barrier at the cathode interface. The counteracting effects of a more favourable cathode contact and increasing bimolecular recombination give rise to an optimum $\mathrm{PCE}$ when the annealing temperature is $140^{\circ} \mathrm{C}$. For temperatures higher than $140^{\circ} \mathrm{C} \mathrm{FF}, J_{S C}$ and $P C E$ sharply reduce, which is likely to be caused by extensive phase segregation. ${ }^{21,22}$ Having determined the optimum annealing temperature, the annealing time was also optimised (Figure $8(\mathrm{~b})$ ). The same trend as seen in Figure 8(a) is also seen in Figure 8(b), where $V_{O C}$ increases while $F F$ decreases. However, $F F$ did not drop below 0.28 and consequently the sharp drop in $J_{S C}$ and $P C E$ was not observed for annealing times up to $30 \mathrm{~min}$. It seems that annealing times $>30 \mathrm{~min}$ are necessary to induce extensive over-segregation of the moieties. However, the microstructure does change almost immediately when placed on the hotplate as is evident by the reduction in $F F$ and increase in $V_{O C}$. The latter two effects give rise to an optimum $P C E$ for an annealing temperature of $140{ }^{\circ} \mathrm{C}$ and an annealing time of $4 \mathrm{~min}$. The improved energy barrier at the cathode interface induces a higher effective voltage (Figure 2), which is why $J_{S C}$ does not significantly change with annealing time despite a reducing $F F$.

\section{CONCLUSIONS}

Unlike BHJ devices, P3HT:PCBM NP devices decrease in performance upon annealing unless a $\mathrm{Ca}$ interface layer is used. The mechanism of this Ca-induced effect was investigated using $I-V$ characteristics, EQE measurements, and XPS depth profiling measurements. The presence of a $\mathrm{Ca}$ interface layer causes PCBM to preferentially migrate to the cathode interface when heated above the glass transition temperature. This PCBM migration changes the contact between the cathode and the active layer from a P3HT dominated contact to a PCBM dominated contact, which in turn gives rise to a larger built-in voltage and directly improves charge extraction from the PCBM moiety. Any annealing treatment above the glass transition temperature results in a decline in $F F$ irrespective of the presence of $\mathrm{Ca}$, which is attributed to increased recombination due to an unfavourable change in the microstructure of the photoactive layer. However, the considerable increase in effective voltage of $\mathrm{NP}$ devices with a $\mathrm{Ca}-\mathrm{Al}$ cathode compensates for the reduction in $F F$ and leads to an increase in $P C E$. PCBM migration occurs in $\mathrm{BHJ}$ devices without the need for $\mathrm{Ca}$, which indicates that the NP structure is less affected by temperature fluctuations and may provide a more thermally stable alternative to the standard BHJ structure. Furthermore, unlike an equivalent BHJ structure, annealing trends show that NP structures are relatively stable until a temperature of $140{ }^{\circ} \mathrm{C}$, after which a sharp decline in $F F, J_{S C}$, and $P C E$ is observed. This decline is attributed to extensive phase segregation as shown in previous studies. ${ }^{21,22}$ The annealing trends of NP devices with a $\mathrm{Ca}-\mathrm{Al}$ cathode were also fully explained by the Ca-induced PCBM migration mechanism. The competition between a decline in $F F$ and increase in $V_{0}$ (which assists in increasing $J_{S C}$ and causes a significant increase in $\left.V_{O C}\right)$ gives rise to an optimum annealing temperature and duration of $140^{\circ} \mathrm{C}$ and $4 \mathrm{~min}$, respectively.

\section{ACKNOWLEDGMENTS}

This work was supported by the Australian Government through the Australian Renewable Energy Agency. The Indonesian Directorate General of Higher Education (DIKTI) is acknowledged for PhD scholarship funding (S.U. and E.S.). This work was performed in part at the Materials node of the Australian National Fabrication Facility, which is a company established under the National Collaborative Research Infrastructure Strategy to provide nano and microfabrication facilities for Australia's researchers.

${ }^{1}$ K. Feron, W. J. Belcher, C. J. Fell, and P. C. Dastoor, Int. J. Mol. Sci. 13, 17019 (2012) 
${ }^{2}$ L. Dou, J. You, Z. Hong, Z. Xu, G. Li, R. A. Street, and Y. Yang, Adv. Mater. 25, 6642 (2013).

E. M. Ward, P. a Schulte, K. Straif, N. B. Hopf, J. C. Caldwell, T. Carreón, D. M. DeMarini, B. a Fowler, B. D. Goldstein, K. Hemminki, C. J. Hines, K. H. Pursiainen, E. Kuempel, J. Lewtas, R. M. Lunn, E. Lynge, D. M. McElvenny, H. Muhle, T. Nakajima, L. W. Robertson, N. Rothman, A. M. Ruder, M. K. Schubauer-Berigan, J. Siemiatycki, D. Silverman, M. T. Smith, T. Sorahan, K. Steenland, R. G. Stevens, P. Vineis, S. H. Zahm, L. Zeise, and V. J. Cogliano, Environ. Heal. Perspect. 118, 1355 (2010).

${ }^{4}$ A. M. Ruder, Ann. N.Y. Acad. Sci. 1076, 207 (2006).

${ }^{5}$ S. Bertho, G. Janssen, T. J. Cleij, B. Conings, W. Moons, A. Gadisa, J. D'Haen, E. Goovaerts, L. Lutsen, J. Manca, and D. Vanderzande, Sol. Energy Mater. Sol. Cells 92, 753 (2008).

${ }^{6}$ W. Ma, C. Yang, X. Gong, K. Lee, and A. J. Heeger, Adv. Funct. Mater. 15, 1617 (2005)

${ }^{7}$ J. Zhao, A. Swinnen, G. Van Assche, J. Manca, D. Vanderzande, and B. Van Mele, J. Phys. Chem. B 113, 1587 (2009).

${ }^{8}$ C. H. Woo, B. C. Thompson, B. J. Kim, M. F. Toney, and J. M. J. Fréchet, J. Am. Chem. Soc. 130, 16324 (2008).

${ }^{9}$ M. Drees, H. Hoppe, C. Winder, H. Neugebauer, N. S. Sariciftci, W. Schwinger, F. Schäffler, C. Topf, M. C. Scharber, Z. Zhu, and R. Gaudiana, J. Mater. Chem. 15, 5158 (2005).

${ }^{10}$ K. Sivula, Z. T. Ball, N. Watanabe, and J. M. J. Fréchet, Adv. Mater. 18, 206 (2006).

${ }^{11}$ K. B. Burke, A. J. Stapleton, B. Vaughan, X. Zhou, A. L. D. Kilcoyne, W. J. Belcher, and P. C. Dastoor, Nanotechnology 22, 265710 (2011).

${ }^{12}$ S. Ulum, N. Holmes, D. Darwis, K. Burke, A. L. David Kilcoyne, X. Zhou, W. Belcher, and P. Dastoor, Sol. Energy Mater. Sol. Cells 110, 43 (2013).

${ }^{13}$ A. Stapleton, B. Vaughan, B. Xue, E. Sesa, K. Burke, X. Zhou, G. Bryant, O. Werzer, A. Nelson, A. L. David Kilcoyne, L. Thomsen, E. Wanless, W. Belcher, and P. Dastoor, Sol. Energy Mater. Sol. Cells 102, 114 (2012).

${ }^{14}$ R. Steim, F. R. Kogler, and C. J. Brabec, J. Mater. Chem. 20, 2499 (2010).

${ }^{15}$ B. Vaughan, A. Stapleton, B. Xue, E. Sesa, X. Zhou, G. Bryant, W. Belcher, and P. Dastoor, Appl. Phys. Lett. 101, 053901 (2012).

${ }^{16}$ K. Landfester, R. Montenegro, U. Scherf, R. Güntner, U. Asawapirom, S. Patil, D. Neher, and T. Kietzke, Adv. Mater. 14, 651 (2002).
${ }^{17}$ K. Feron, T. J. Nagle, L. J. Rozanski, B. B. Gong, and C. J. Fell, Sol. Energy Mater. Sol. Cells 109, 169 (2013).

${ }^{18}$ K. Feron, C. J. Fell, L. J. Rozanski, B. B. Gong, N. Nicolaidis, W. J. Belcher, X. Zhou, E. Sesa, B. V. King, and P. C. Dastoor, Appl. Phys. Lett. 101, 193306 (2012).

${ }^{19}$ C. G. Shuttle, R. Hamilton, B. C. O'Regan, J. Nelson, and J. R. Durrant, Proc. Natl. Acad. Sci. U.S.A. 107, 16448 (2010).

${ }^{20}$ R. C. I. MacKenzie, T. Kirchartz, G. F. A. Dibb, and J. Nelson, J. Phys. Chem. C 115, 9806 (2011).

${ }^{21}$ N. P. Holmes, K. B. Burke, P. Sista, M. Barr, H. D. Magurudeniya, M. C. Stefan, A. L. D. Kilcoyne, X. Zhou, P. C. Dastoor, and W. J. Belcher, Sol. Energy Mater. Sol. Cells 117, 437 (2013).

${ }^{22}$ K. Feron, S. Ulum, N. P. Holmes, A. L. D. Kilcoyne, W. J. Belcher, X. Zhou, C. J. Fell, and P. C. Dastoor, Appl. Phys. Lett. 103, 193306 (2013).

${ }^{23}$ H. Won Choi, S. Young Kim, K.-B. Kim, Y.-H. Tak, and J.-L. Lee, Appl. Phys. Lett. 86, 012104 (2005).

${ }^{24}$ See supplementary material at http://dx.doi.org/10.1063/1.4896249 for the empirical relationship between effective voltage and light intensity, details on interface matching and the calculation of $\mathrm{C}_{\mathrm{a} / \mathrm{p}}$.

${ }^{25}$ N. C. Nicolaidis, B. S. Routley, J. L. Holdsworth, W. J. Belcher, X. Zhou, and P. C. Dastoor, J. Phys. Chem. C 115, 7801 (2011).

${ }^{26} \mathrm{~W}$. Möller and M. Posselt, TRIDYN-FZR User Manual (2001).

${ }^{27}$ X. Bulliard, S.-G. Ihn, S. Yun, Y. Kim, D. Choi, J.-Y. Choi, M. Kim, M. Sim, J.-H. Park, W. Choi, and K. Cho, Adv. Funct. Mater. 20, 4381 (2010).

${ }^{28}$ D. S. Germack, C. K. Chan, B. H. Hamadani, L. J. Richter, D. a. Fischer, D. J. Gundlach, and D. M. DeLongchamp, Appl. Phys. Lett. 94, 233303 (2009).

${ }^{29}$ R. Walder, A. Honciuc, and D. K. Schwartz, Langmuir 26, 1501 (2010).

${ }^{30}$ P. Burgos, Z. Zhang, R. Golestanian, G. J. Leggett, and M. Geoghegan, ACS Nano 3, 3235 (2009).

${ }^{31}$ Y.-S. Kim, T. Kim, B. Kim, D.-K. Lee, H. Kim, B.-K. Ju, and K. Kim, Org. Electron. 14, 1749 (2013).

${ }^{32}$ C. Zhang, S. Tong, C. Jiang, E. Kang, D. S. H. Chan, and C. Zhu, IEEE Trans. Electron Devices 57, 397 (2010).

${ }^{33}$ L. J. A. Koster, V. D. Mihailetchi, R. Ramaker, and P. W. M. Blom, Appl. Phys. Lett. 86, 123509 (2005).

${ }^{34}$ D. Credgington, R. Hamilton, P. Atienzar, J. Nelson, and J. R. Durrant, Adv. Funct. Mater. 21, 2744 (2011) 